\title{
Study on Borehole Arrangement Methods for Gas Extraction by Hydraulic Slotting in Long-Distance Through-Coal Seam Tunnel
}

\author{
Cunfang Zhu ${ }^{1}$ and Shuang Cai ${ }^{2}{ }^{2}$ \\ ${ }^{1}$ Qinghai Local Railway Construction Investment Co. Ltd., Xining 810001, China \\ ${ }^{2}$ China Merchants Chongqing Communication Research \& Design Institute Co., Ltd., Chongqing 400067, China \\ Correspondence should be addressed to Shuang Cai; caishuang@cmhk.com
}

Received 19 August 2020; Revised 17 September 2020; Accepted 28 September 2020; Published 28 October 2020

Academic Editor: Bin-Wei Xia

Copyright (c) 2020 Cunfang Zhu and Shuang Cai. This is an open access article distributed under the Creative Commons Attribution License, which permits unrestricted use, distribution, and reproduction in any medium, provided the original work is properly cited.

\begin{abstract}
How to quickly eliminate outburst in long-distance through-coal seam tunnels is one of the major challenges faced by the tunnel industry in mountainous areas. Compared with coal mine rock crosscut coal uncovering, the work surrounding the rock of through-coal seam tunnels has a high degree of breakage, large cross-section of coal uncovering, and tight time and space. In this paper, a method of networked slotting in long-distance through-coal seam tunnels for rapid pressure relief and outburst elimination is proposed. Based on this method, the corresponding mathematical governing equations and numerical simulation models have been established. The optimal borehole arrangement spacing and the slot arrangement spacing obtained by numerical optimization are $2.85 \mathrm{~m}$ and $3.1 \mathrm{~m}$, respectively. Field gas production data of through-coal seam tunnels show that compared with the traditional dense-borehole gas extraction, the method of networked slotting in long-distance through-coal seam tunnels for rapid pressure relief and outburst elimination can shorten the extraction time by about $66 \%$, the net quantity of peak extraction is increased by 3.55 times, and the total quantity of gas extraction when reaching the outburst prevention index is increased by 1.26 times, which verifies the feasibility of this method and the reliability of numerical simulation results. This study could be used as a valuable example for other coal deposits being mined under similar geological conditions.
\end{abstract}

\section{Introduction}

With the rapid development of the national economies of the world, high-speed tunnels and railways have formed a comprehensive transportation system for modern cities to communicate and connect with each other. However, in some countries with complex terrain, mountainous areas rich in various lithologies will be encountered in the process of tunnel construction, which makes tunnel construction particularly difficult. As a representative of typical mountainous countries, China's mountainous area accounts for two-thirds of the country's total area. Especially in the face of the country's vigorous development of the central and western regions, China will usher in a new upsurge in the construction of large-scale projects of transport infrastructures such as highspeed railways and expressways. In addition to the complexity of mountainous terrain, there are many strata with developed coal measures in western China, which make gas tunnels an unavoidable challenge in the construction of transport infrastructures. According to incomplete statistics, in the recent 20 years, more than 70 gas tunnels have been built in China, penetrating more than 300 coal seams [1]. The critical technical problems brought by unfavorable geological conditions of coal measure strata in mountainous areas are one of the challenges that we need to solve urgently.

Due to the complexity of the geological structures of coal measure strata, weak and broken rock mass, and high gas pressure, large deformation or even instability and collapse of surrounding rocks and various gas disasters are likely to occur. In the process of tunnel coal seam uncovering, the instable failure of coal rock mass in the original high geostress field and high gas pressure field induces coal and gas outburst accidents, which is a kind of disaster with the highest intensity and the greatest danger. Gas tunnel construction in China started fairly late, and there is no complete set of technical systems of tunnel coal uncovering and outburst prevention formed. 
The research on tunnel gas disaster mainly focuses on risk assessment, construction safety management, and monitoring of surrounding rock deformation, while the research on outburst prevention technology is little. As a result, the technology of coal uncovering and outburst prevention measures in through-coal seam tunnels lags far behind the development of on-site production practice $[2,3]$.

The existing design and construction of through-coal seam tunnels are mainly based on the relevant theories and experiences of coal mine underground rock crosscut coal uncovering or coal roadway driving. Through-coal seam tunnels and underground coal mine roadway driving have some similarities in excavation and construction, but there are also obvious differences, especially the characteristics of large tunnel section and tight time and space for implementing outburst prevention measures, which make the difficulty and risk of coal uncovering much higher than that of coal mine rock crosscut coal uncovering. Therefore, it is unscientific to directly use the outburst prevention technology of coal mine rock crosscut coal uncovering to guide the construction of gas tunnels, and it is badly in need of research on the outburst prevention technology regarding the characteristics of gas tunnels. Li et al. [4], Jiang et al. [5], Wang and Li. [6], etc. have carried out researches on tunnel coal uncovering technologies from the aspects of exploration, prediction, and prevention and control and have achieved fruitful results. However, due to the extremely low gas permeability coefficient (as low as $0.01 \mathrm{mD}$ ) of most coal seams in Southwest China, the effect of conventional permeabilityenhancing technologies is poor, and it takes a long time to eliminate outburst and reach the standard. Cheng et al. [79], Lu et al. [10], Feng and Kang [11] Wang et al. [12], etc. have studied preextraction coal seam permeability enhancement after coal mine underground hydraulic slotting, and practices have shown that this technology can quickly and extensively enhance the coal seam permeability and the preextraction effect, laying a foundation for quickly eliminating the danger of gas outburst $[13,14]$.

By analyzing the characteristics of gas disaster prevention in long-distance through-coal seam tunnels, this paper puts forward the method of networked slotting in long-distance through-coal seam tunnels for rapid pressure relief and outburst elimination, carries out theoretical and numerical analysis on the arrangement parameters of boreholes and hydraulic slots for long-distance through-coal seam tunnels, and verifies the reliability of this method through field tests of a gas tunnel in Qinghai, China, thus providing technical support for the technical system of rapid coal uncovering and outburst elimination in long-distance through-coal seam tunnels.

\section{Analysis on Technical Challenges of Outburst Elimination in Through-Coal Seam Tunnels}

Long-distance excavation of tunnels along the coal seam strike and through-coal seams actually has something in common with coal mine roadway driving, but also has its particularity. To sum up, the main differences are the following:
(1) The buried depth of gas tunnels is generally not more than $300 \mathrm{~m}$, and the surrounding rocks have high degree of breakage affected due to weathering. Compared with the buried depth up to nearly one kilometer of coal mines, gas tunnels are more affected by excavation disturbance, and the possibility of instability of tunnel-surrounding rocks is higher

(2) Before mining, coal mines generally have detailed geological survey data, but the geological survey of gas tunnels is affected by many factors, which leads to a low degree of geological survey. Therefore, the formulated outburst prevention measures may not meet the needs of actual geological conditions

(3) The cross-section of through-coal seam tunnels is larger than that of coal mine roadway driving. The cross-section of coal mine roadways is small, generally not more than $20 \mathrm{~m}^{2}$, while the cross-section of gas tunnels is large. At present, the excavation section of double-line highway tunnels has exceeded $110 \mathrm{~m}^{2}$, and the excavation section of double-line railway tunnels is even close to $150 \mathrm{~m}^{2}$

(4) For through-coal seam tunnels, outburst prevention is difficult and the time is tight, which is because the advanced mining deployment of coal mines leaves plenty of time and space for the implementation of outburst prevention measures, while a gas tunnel has only a single working face, making it impossible to implement outburst prevention measures ahead of time

(5) The cross-section excavation of tunnels causes frequent disturbance to the coal seam, while coal mine roadways generally adopt the method of full crosssection uncovering of coal seam at one time. In order to reduce the energy released during uncovering of coal and reduce the outburst danger, large-section tunnels often adopt the method of multiple-section partitioned coal uncovering, which is disturbed frequently by external forces and has more complex dynamic response characteristics

(6) Through-coal seam tunnels have higher requirement for roadway support. The service life of roadways in a coal mining area will be abandoned after coal mining, and large deformation of roadway is allowed, while the service period of tunnels is long, generally ranging from several decades to one hundred years, and large deformation or large amount of gas emission is not allowed during the service period

(7) Compared with the available circulating space in coal mines, gas tunnels' single-roadway ventilation with a length of up to one kilometer makes it more difficult to exhaust smoke and dilute gas

In summary, when excavating and uncovering coal in gas tunnels, it is necessary to consider the similarities and differences between long-distance through-coal seam tunnels and coal mine roadway driving according to specific engineering 
conditions, take targeted outburst prevention measures with low damage to surrounding rocks on the premise of accurately predicting outburst dangers, and make timely adjustment according to the characteristics of dynamic behaviors to ensure safe and rapid uncovering of coal seams. This requires that the preextraction of gas in gas tunnels before mining needs the characteristics of less disturbance to the surrounding rocks of roadways, short gas emission period, high efficiency, etc.

According to the method of networked slotting in longdistance through-coal seam tunnels for rapid pressure relief and outburst elimination proposed in this paper, it is necessary to use as few boreholes and slots as possible to achieve the highest extraction efficiency, so as to meet the requirements of outburst prevention in gas roadways or tunnels. In this paper, through numerical analysis and field test verification on key parameters of borehole arrangement spacing and hydraulic slot arrangement spacing for preextraction of gas tunnels, it is intended to obtain the optimal borehole arrangement spacing and slotting that meets the gas preextraction index.

\section{Mathematical Model Equations}

3.1. Coal Mass Deformation Equation. Assuming that thermal expansion/contraction and matrix expansion/contraction are isotropic, the constitutive relation of a nonisothermal deformed coal seam can be written as (compression negative) $[15,16]$

$$
\begin{aligned}
\varepsilon_{i j} & =\frac{1}{2 G} \sigma_{i j}-\left(\frac{1}{6 G}-\frac{1}{9 k}\right) \sigma_{k k} \delta_{i j}+\frac{\alpha}{3 K} p_{m} \delta_{i j} \\
& +\frac{\beta}{3 K} p_{f} \delta_{i j}+\frac{\alpha_{T}}{3} T \delta_{i j}+\frac{\varepsilon_{s}}{3} \delta_{i j},
\end{aligned}
$$

where $\sigma_{i j}$ and $\delta_{i j}$, respectively, represent total stress tensor and total strain tensor. $G=D / 2(1+v), D=\left[1 / E+1 / a K_{n}\right]^{-1}, K=$ $D / 3(1-2 v), \alpha=1-K / K_{s}$, and $\beta=1-K / a \cdot K_{n}$, and $K$ is the bulk modulus of coal, $K_{s}$ is the bulk modulus of the coal matrix, $K_{n}$ is the normal stiffness of a single fissure, $E$ is Young's modulus of coal, $G$ is the shear modulus, $v$ is Poisson's ratio, $\alpha$ and $\beta$ are coefficients of consolidation, $\delta_{i j}$ is the Kronecker symbol, and $p$ is pore pressure. In the following tables, $f$ and $m$ represent matrix and fracture parameters, respectively; $T$ is the coal reservoir temperature; and $\alpha_{T}$ is the thermal expansion coefficient of the coal matrix. Based on Equation (1), the volumetric strain $\varepsilon_{v}$ is

$$
\varepsilon_{v}=-\frac{1}{K}\left(\bar{\sigma}-\alpha p_{m}-\beta p_{f}\right)+\alpha_{T} T+\varepsilon_{s}
$$

where $\varepsilon_{v}=\varepsilon_{11}+\varepsilon_{22}+\varepsilon_{33}$ is the volumetric strain of coal mass; $\bar{\sigma}=-\sigma_{k k} / 3$ is mean compressive stress. The volumetric strain $\varepsilon_{s}$ generated by adsorption satisfies Langmuir-type curves, which can be calculated by Langmuir-type equations:

$$
\varepsilon_{s}=\varepsilon_{L} \frac{p_{m}}{p_{m}+p_{L}},
$$

where $\varepsilon_{L}$ is the Langmuir volumetric strain constant, representing the maximum volumetric strain caused by adsorption, and $P_{L}$ is the Langmuir pressure constant.

The stress balance equation and geometric equation of coal containing gas can be expressed as

$$
\begin{gathered}
\sigma_{i j, j}+f_{i}=0, \\
\varepsilon_{i j}=\frac{1}{2}\left(u_{i, j}+u_{j, i}\right),
\end{gathered}
$$

where $f_{i}$ is the body force component and $u_{i}$ is the deformation displacement in the $i$ direction. Combining Equations (1)-(5) and sorting them out, the Navier-type coal mass deformation equation can be obtained:

$$
\begin{gathered}
G u_{i, j j}+\frac{G}{1-2 v} u_{j, i i}-\beta_{m} p_{m, i}-\beta_{f} p_{f, i}-K \alpha_{T} T_{, i} \\
-K \varepsilon_{L} \frac{P_{L}}{p_{m}+P_{L}} p_{m, i}+f_{i}=0 .
\end{gathered}
$$

3.2. Coal Seam Gas Flow Equation. The gas flow in coal seams follows the mass balance equation:

$$
\frac{\partial m}{\partial t}+\nabla \cdot\left(\rho_{g} \mathbf{q}\right)=Q_{S}
$$

where $m$ is the gas mass per unit volume of coal, $\rho_{g}$ is the gas density in coal mass, $\mathbf{q}$ is the velocity vector of Darcy's law, and $Q_{S}$ is the source item or sink item of gas. Assuming that gas adsorption only occurs in the coal matrix, the gas occurrence mass per unit volume of coal matrix $m_{m}$ and the gas occurrence mass in fissures $m_{k}$ can be expressed as

$$
\begin{gathered}
m_{m}=\phi_{m} \rho_{g m}+\rho_{n} \rho_{c} \frac{V_{L} p_{m}}{p_{m}+P_{L}}, \\
m_{f}=\phi_{f} \rho_{g f},
\end{gathered}
$$

where $\rho_{g m}$ and $\rho_{g f}$, respectively, represent the gas density in coal matrix and coal mass fissures; $\phi_{m}$ and $\phi_{f}$, respectively, represent the coal matrix porosity and coal fissure porosity; $\rho_{n}$ is the gas density under the standard condition; and $\rho_{c}$ is the density of coal. According to the equation of the state of ideal gas, the relationship between gas density and pressure can be expressed as

$$
\rho_{g}=\frac{M_{g}}{R T} p,
$$

where $M_{g}$ is the molar mass of gas and $R$ is the universal gas constant.

The mass exchange rate of gas between matrix and fissures is determined by the difference of gas content, which is directly proportional to gas pressure [17]:

$$
Q_{S}=\frac{\rho_{g m} k_{m} \psi}{\mu}\left(p_{m}-p_{f}\right),
$$


where $\psi=4\left(1 / a_{x}^{2}+1 / a_{y}^{2}\right)$ is the shape factor of coal and $a_{x}$ and $a_{y}$ are the lengths of the coal matrix.

Because the gaseous mass of gas is very small, ignoring the influence of gravity on the flow and diffusion process of gas in the coal seam and assuming that methane migration in coal seams is laminar, the velocity vector of gas can be obtained according to Darcy's law as follows:

$$
\mathbf{q}_{\mathbf{g}}=-\frac{k}{\mu} \nabla p
$$

Substituting Equations (8)-(11) into Equation (7) and sorting it out, the governing equation of coal matrix gas pressure changing with time can be obtained. The governing equation of gas migration in a dual-porosity media model is

$$
\begin{gathered}
\frac{\partial m_{m}}{\partial t}+\nabla\left(-\frac{k_{m}}{\mu} \rho_{g m} \nabla p_{m}\right)=-\frac{\rho_{m} k_{m} \psi}{\mu}\left(p_{m}-p_{f}\right) \\
\phi_{f} \frac{\partial \rho_{f g}}{\partial t}+\rho_{g f} \frac{\partial \phi_{f}}{\partial t}+\nabla\left(-\frac{k_{f}}{\mu} \rho_{g f} \nabla p_{f}\right)=\frac{\rho_{m} k_{m} \psi}{\mu}\left(p_{m}-p_{f}\right) .
\end{gathered}
$$

The porosity change in the coal matrix can be expressed by the following equation [18]:

$$
\phi_{m}=\frac{1}{1+S}\left[\left(1+S_{0}\right) \phi_{m 0}+\alpha\left(S-S_{0}\right)\right]
$$

where

$$
\begin{gathered}
S=\varepsilon_{v}+\frac{p_{m}}{K_{s}}-\varepsilon_{s}-\alpha_{T} T \\
S_{0}=\varepsilon_{v 0}-\frac{p_{m 0}}{K_{s}}-\varepsilon_{L} \frac{p_{m 0}}{p_{m 0}+P_{L}}-\alpha_{T} T_{0} .
\end{gathered}
$$

The permeability and porosity of the coal matrix meet the following relationship [19]:

$$
\frac{k}{k_{0}}=\left(\frac{\phi}{\phi_{0}}\right)^{3} \text {. }
$$

Bring Equation (14) into Equation (16), and coal matrix permeability

$$
k_{m}=k_{m 0}\left(\frac{1}{1+S}\left[\left(1+S_{0}\right)+\frac{\alpha}{\phi_{m 0}}\left(S-S_{0}\right)\right]\right)^{3} \text {. }
$$

Considering the anisotropy of the permeability of coal mass fissures, for a 2D model, the porosity and permeability in coal mass fissures can be calculated by the following equations [20]:

$$
\begin{gathered}
\frac{\phi_{f}}{\phi_{f 0}}=1+2\left(1-R_{m}\right)\left(\Delta \varepsilon_{v}-\alpha_{T} \Delta T-\Delta \varepsilon_{s}\right) \\
\frac{k_{f i}}{k_{f 0}}=\left[1+\frac{2\left(1-R_{m}\right)}{\phi_{f 0}}\left(\Delta \varepsilon_{j}-\frac{1}{3} \alpha_{T} \Delta T-\frac{1}{3} \Delta \varepsilon_{s}\right)\right]^{3}, \quad i \neq j .
\end{gathered}
$$

3.3. Heat Conduction Equation. Assuming that the constitutive equation of heat conduction satisfies Fourier's law, ignoring the interchangeability of thermal energy and mechanical energy, and considering that the temperature field in a binary medium is unitary, the heat transfer equation in the coal seam of a dual porosity model can be expressed as $[21,22]$

$$
\begin{gathered}
(p C)_{M} \frac{\partial T}{\partial t}+T K_{g} \alpha_{g}\left(\nabla \mathbf{q}_{\mathbf{g m}}+\nabla \mathbf{q}_{\mathbf{g f}}\right)+T K \alpha_{T} \frac{\partial \varepsilon_{v}}{\partial t} \\
=\lambda_{m} \nabla^{2} T-\rho_{\mathbf{g} m} \mathbf{q}_{\mathbf{g m}} C_{g} \nabla T-\rho_{\mathbf{g} f} \mathbf{q}_{\mathbf{g f}} C_{g} \nabla T,
\end{gathered}
$$

where $\lambda_{M}=\left(\phi_{m}+\phi_{f}\right) \lambda_{g}+\left(1-\phi_{m}-\phi_{f}\right) \lambda_{s}$ and $\lambda_{g}$ and $\lambda_{s}$ are the thermal conductivity coefficients of solid and fluid components, respectively. $(p C)_{M}=\phi_{m}\left(\rho_{g m} C_{g}\right)+\phi_{f}\left(\rho_{g f} C_{g}\right)$ $+\left(1-\phi_{m}-\phi_{f}\right)\left(\rho_{c} C_{s}\right)$ is the heat capacity of porous media containing fluid; $C_{g}$ and $C_{s}$ are the specific heat capacities of a fluid and solid under constant volume, respectively; $K_{g}$ is the volume modulus of pore gas; and $\alpha_{g}=1 / T$ is the thermal expansion coefficient of gas.

\section{Project Overview and Calculation Model}

A highway tunnel in Qinghai is $6024 \mathrm{~m}$ long with a buried depth of $116-452 \mathrm{~m}$. The surrounding rock of the tunnel is an interbedding of strongly-moderately weathered macker, coal seams, and sandstone, and the rock mass has an argillaceous texture and thin-lamellar structure, which is fairly broken. The main mineral is argillaceous mineral. Due to the influence of stratum engineering geological conditions, the joints and fissures in this section are developed, the rock mass is broken, and the stability of the surrounding rock is poor, showing a cataclastic texture. According to the detection result, the left and right tunnels of this tunnel have more than $1,400 \mathrm{~m}$ or even longer sections passing through the coal seam gas area. The average thickness of the coal seam is $1.98 \mathrm{~m}$, and the measured gas content and pressure are $11.5 \mathrm{~m}^{3} / \mathrm{t}$ and 1.2 $\mathrm{MPa}$, respectively, which has an extremely high risk of coal and gas outburst. In order to improve the tunneling efficiency and quickly eliminate the danger of coal and gas outburst in the exposed coal seam, the water jet slotting technology was used to achieve permeability enhancement and gas extraction from the coal seam efficiently [23-25]. To optimize the slot arrangement in boreholes, a numerical model was established (as shown in Figure 1) to study the gas distribution in the coal seam and along the monitoring line under different slot arrangement modes. An unstructured triangular mesh domain in the numerical model is created. All the results obtained in this study are independent of mesh size and time 


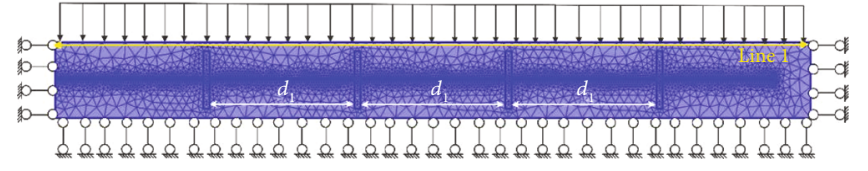

(a)

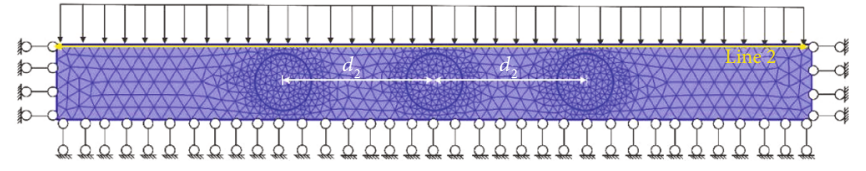

(b)

FIGURE 1: Schematic diagram of numerical simulation and corresponding boundary conditions.

TABLE 1: Main parameters for numerical simulation.

\begin{tabular}{lc}
\hline Model parameter & Parameter value \\
\hline Model size $(\mathrm{m})$ & $20 \times 1.98$ \\
Simulated buried depth $(\mathrm{m})$ & $200 \mathrm{~m}$ \\
Young's modulus of coal $E(\mathrm{MPa})$ & 1900 \\
Young's modulus of coal matrix $E_{s}(\mathrm{MPa})$ & 8469 \\
Poisson's ratio of coal $v$ & 0.23 \\
Apparent density of coal $\rho_{c}\left(\mathrm{~kg} / \mathrm{m}^{3}\right)$ & 1400 \\
$\mathrm{CH}_{4}$ Langmuir volume constant $V_{L}\left(\mathrm{~m}^{3} / \mathrm{t}\right)$ & 17.1 \\
$\mathrm{CH}_{4}$ Langmuir pressure constant $P_{L}(\mathrm{MPa})$ & 1.729 \\
$\mathrm{CH}_{4}$ dynamic viscosity $\mu(\mathrm{Pa} \cdot \mathrm{s})$ & $1.84 \times 10^{-5}$ \\
Borehole temperature $(\mathrm{k})$ & 293.15 \\
Initial coal mass fissure permeability $k_{f 0}\left(\mathrm{~m}^{2}\right)$ & $5.9 \times 10^{-17}$ \\
Initial coal matrix permeability $k_{m 0}\left(\mathrm{~m}^{3}\right)$ & $1 \times 10^{-18}$ \\
Initial matrix porosity $\phi_{m}$ & 0.07 \\
Initial coal seam temperature $T(\mathrm{~K})$ & 303 \\
Maximum adsorption deformation of coal $\varepsilon_{L}$ & 0.025 \\
Coefficient of thermal expansion of & $2.4 \times 10^{-5}$ \\
coal matrix $\alpha_{T}\left(\mathrm{~K}^{-1}\right)$ & $1.25 \times 10^{3}$ \\
Specific heat capacity of coal $C_{s}(\mathrm{~J} / \mathrm{kg} \cdot \mathrm{K})$ & $1.625 \times 10^{3}$ \\
Specific heat capacity of gas $C_{g}(\mathrm{~J} / \mathrm{kg} \cdot \mathrm{K})$ & 0.2 \\
Coefficient of heat conduction $\lambda_{s}(\mathrm{~J} / \mathrm{kg} \cdot \mathrm{K})$ & \\
\hline
\end{tabular}

step. Considering the construction efficiency onsite, the designed extraction period was 15 days. The slot length of the slotted borehole was $1.5 \mathrm{~m}$ and the width was $0.165 \mathrm{~m}$, the slot spacing in the same along-seam borehole was $d_{1}$ (Figure 1(a)), and the slot spacing in the same plane of different along-seam boreholes was $d_{2}$ (Figure 1(b)). Parameters of the simulated coal seam are shown in Table 1 .

4.1. Reasonable Slot Spacing in the Same Along-Seam Borehole $d_{1}$. Figure 2 is a nephogram of gas distribution in coal matrix under different slot spacing $d_{1}$ after 15-day extraction. It can be seen from Figure 2 that, under the influence of negative pressure of extraction from the slotted borehole, the closer to the slotted borehole, the faster the gas pressure in the coal seam decreased. With the decrease of the number of slots in the borehole along the seam, the high gas pressure areas in the coal seam gradually increased. So, there is an optimal slot spacing arrangement. In China, the coal seam gas pressure below $0.74 \mathrm{MPa}$ is taken as an index to judge whether the preextraction effect reaches the standard or not. Therefore, the optimal slot spacing $d_{1}$ was

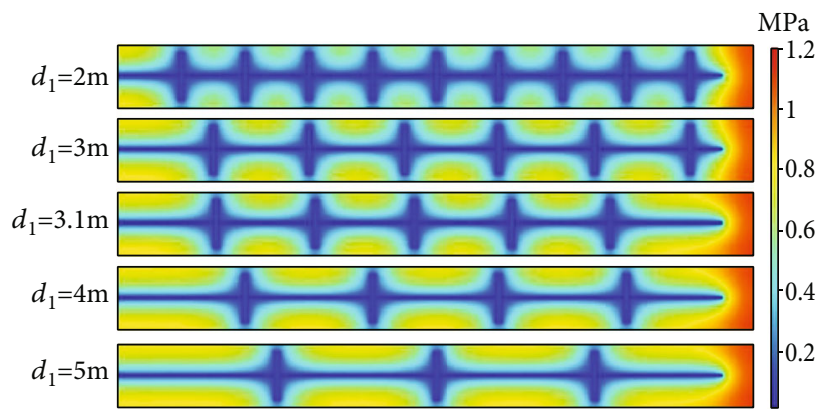

FIGURE 2: Gas pressure distribution in coal matrix under different slot spacing $d_{1}$ after 15-day extraction.

determined by detecting the gas pressure on the boundary monitoring line of the model under different slot spacing $d_{1}$.

It can be seen from Figure 3 that, when the slot spacing was $2 \mathrm{~m}$, the maximum coal matrix gas pressure between slots was $0.57 \mathrm{MPa}$, which was far lower than the index of $0.74 \mathrm{MPa}$, but the number of slots was too much, and it required cutting 9 slots within the $19 \mathrm{~m}$ long borehole along the seam, greatly increasing the construction cost. When the slot spacing was $4 \mathrm{~m}$ or $5 \mathrm{~m}$, the maximum coal matrix gas pressure between slots exceeded $0.74 \mathrm{MPa}$, which was easy to bring the risk of outburst to later coal uncovering. In the end, through simulation, it was found that, when the slot spacing was $3.1 \mathrm{~m}$, the gas pressure between slots was just less than the index value. Therefore, it was suggested that, in this study, the slot spacing in the same along-seam borehole in the coal seam should be designed to be $3.1 \mathrm{~m}$, so as to optimize gas extraction of the coal seam within the extraction area before tunneling.

\subsection{Reasonable Slot Spacing between Different Along-Seam} Borehole $d_{2}$. Figure 4 is a nephogram of gas distribution in the coal matrix under different slot spacing $d_{2}$ after 15-day extraction. Under the joint extraction of multiple slots, the gas pressure in the coal seam decreased, especially in the area between slots. With the increase of slot spacing between different along-seam boreholes, the residual gas pressure of the coal seam between slots gradually increased and gradually exceeded the index value from less than $0.74 \mathrm{MPa}$, which indicates that there is also an optimal slot spacing arrangement between different along-seam boreholes. By extracting the gas pressure of coal matrix on the monitoring line 2 (Figure 5), it was found that, when the slot spacing $d_{2}$ was $2.5 \mathrm{~m}$, the maximum gas pressure in the coal seam between slots was $0.55 \mathrm{MPa}$, which reached the preextraction index. However, this arrangement is too dense, which will increase the construction amount. When the slot spacing $d_{2}$ was 


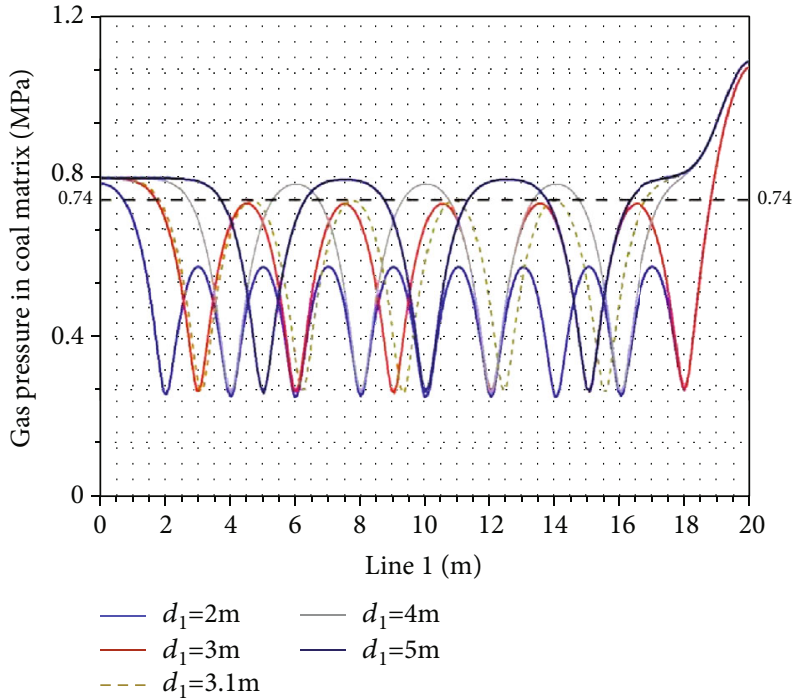

Figure 3: Distribution trend of gas pressure in coal matrix on monitoring line under different slot spacing $d_{1}$.

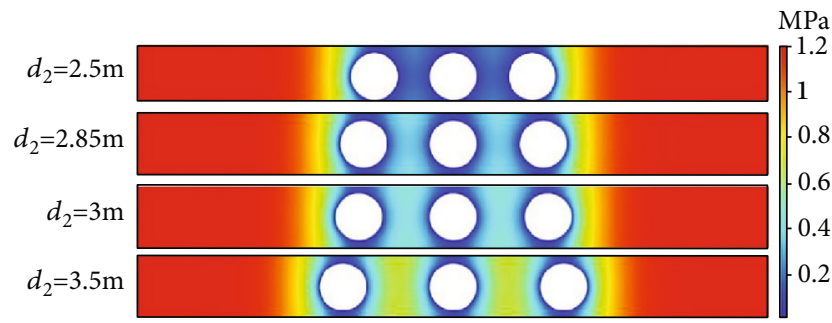

Figure 4: Gas pressure distribution in coal matrix under different slot spacing $d_{2}$ after 15-day extraction.

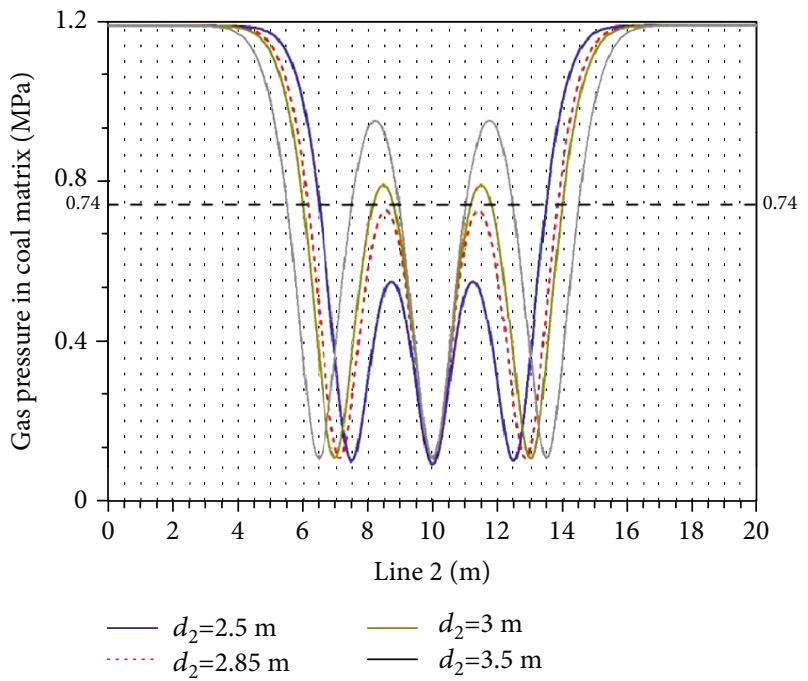

Figure 5: Distribution trend of gas pressure in coal matrix on monitoring line under different slot spacing $d_{2}$.
$2.85 \mathrm{~m}$, the residual gas pressure between slots was $0.72 \mathrm{MPa}$, just reaching the preextraction index. However, when the slot spacing $d_{2}$ exceeded $2.85 \mathrm{~m}$, reaching $3 \mathrm{~m}$ or $3.5 \mathrm{~m}$, the residual gas pressure between slots reached $0.79 \mathrm{MPa}$ and $0.95 \mathrm{MPa}$, respectively, which exceeded the preextraction index value of $0.74 \mathrm{MPa}$, and the gas extraction effect failed to reach the standard. In conclusion, it will be more reasonable to arrange the slot spacing $d_{2}$ between different alongseam boreholes in this coal seam as $2.85 \mathrm{~m}$.

\section{Analysis and Discussion of Application Results}

In order to verify the correctness of the numerical analysis results, hydraulic slotting extraction was carried out at the optimized $2.85 \mathrm{~m}$ along-seam borehole spacing and $3.1 \mathrm{~m}$ slot spacing for the $60 \mathrm{~m}$ pretunneled through-coal seam tunnel. For another section of tunnel with the same length, a single-borehole extraction method was used as a blank controller for analysis, and the borehole spacing of this method was $2 \mathrm{~m}$. A schematic diagram of the borehole design of the two methods is shown in Figure 6.

In order to compare the gas extraction effects of the two methods, we carried out statistical analysis on the field gas extraction, as shown in Figures 7 and 8, which are, respectively, the variations of gas extraction concentration, the net quantity of gas extraction, and the cumulative quantity of gas extraction quantity over time. It can be seen from the statistical data of gas extraction that it took 44 days to meet the outburst prevention requirements with the singleborehole extraction method, while it took only 15 days with the method of extraction after hydraulic slotting, which shortens the extraction period by $2 / 3$ and greatly improves the efficiency. Figure 7 shows that the gas extraction concentration reached the peak concentration of $65 \%$ on the $43 \mathrm{rd}$ day by the single-borehole extraction method, while the gas concentration rose rapidly after hydraulic slotting, reaching the peak concentration of $61 \%$ only on the 8 th day. In Figure 7 , the net quantity of gas extraction of singleborehole extraction kept a relatively gentle trend during the first 35 days, all of which were below $0.2 \mathrm{~m}^{3} / \mathrm{min}$, and after the 35th day, the net quantity of extraction slowly increased to the peak value of $0.31 \mathrm{~m}^{3} / \mathrm{min}$. On the other hand, in the case with hydraulic slotting extraction method, it reached $0.4 \mathrm{~m}^{3} / \mathrm{min}$ on the 2 nd day and quickly increased to the peak value on the 6 th day, about $1.1 \mathrm{~m}^{3} / \mathrm{min}$, which was 3.55 times of the peak value of the net quantity of extraction with the single-borehole extraction method. According to the total quantity of extraction shown in Figure 8, the total quantity of gas extracted with the single-borehole extraction method was $10,011 \mathrm{~m}^{3}$ after the gas pressure was lower than $0.74 \mathrm{MPa}$, while it reached this value on the 11th day with the method of extraction after hydraulic slotting, and after the gas pressure reached the standard, the total quantity of extraction reached $12,585.6 \mathrm{~m}^{3}$, which was about 1.26 times that of the unslotted extraction method. The data in Figures 7 and 8 show that, compared with the traditional single-borehole extraction method, the long-distance through-coal seam tunnel adopting the method of hydraulic 


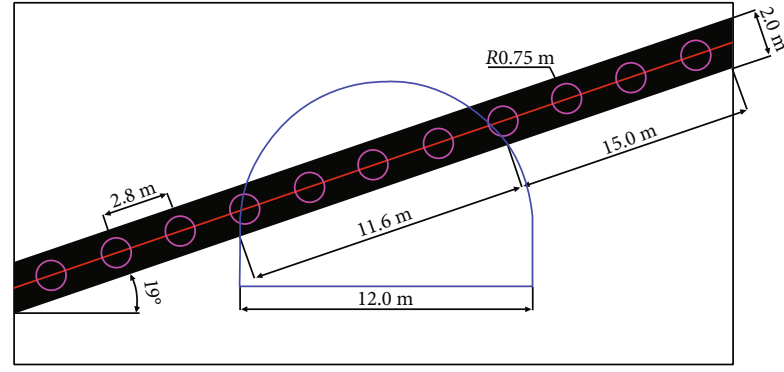

FIGURE 6: Schematic diagram of borehole arrangement for singleborehole extraction and hydraulic slotting extraction.
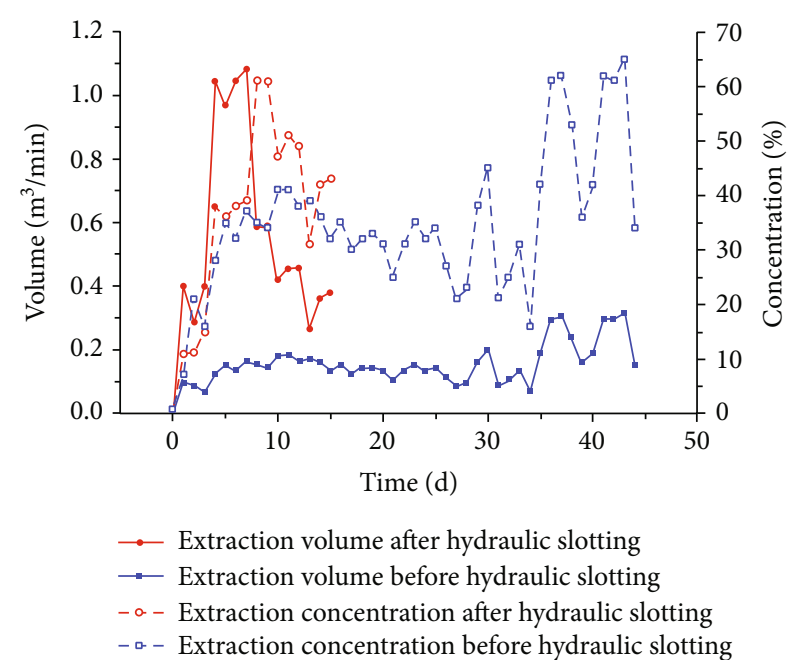

Figure 7: Gas extraction vs. time.

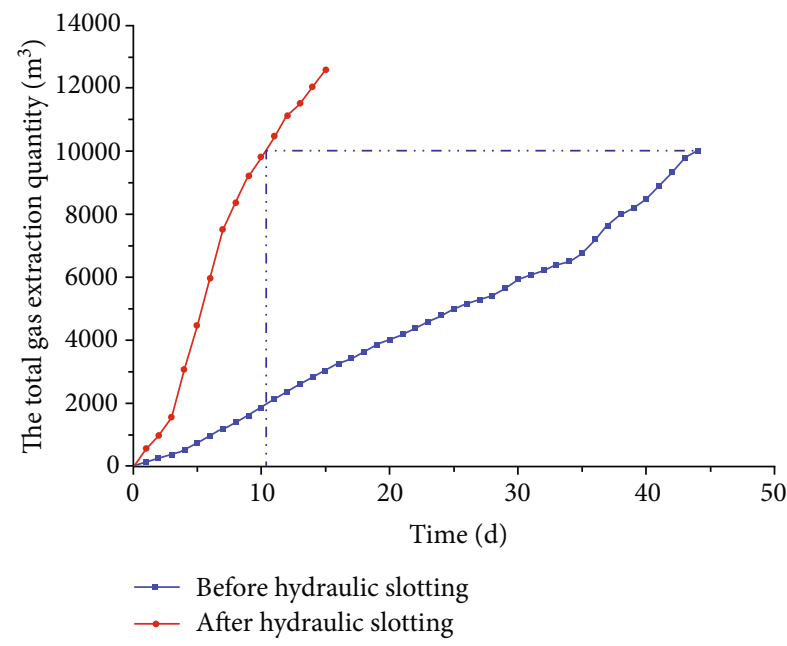

Figure 8: Total quantity of gas extraction vs. time.

slotting for quick pressure relief and gas extraction can quickly shorten the construction period, save the workload, and achieve the extraction outburst prevention index.

The residual gas quantity and residual gas pressure obtained with the two extraction methods are shown in Table 2. Both of the cases can meet the outburst prevention
TABLE 2: Outburst prevention index after extraction.

\begin{tabular}{cccc}
\hline S/N & Extraction method & $\begin{array}{c}\text { Residual gas } \\
\text { content }\left(\mathrm{m}^{3} / \mathrm{t}\right)\end{array}$ & $\begin{array}{c}\text { Residual gas } \\
\text { pressure (MPa) }\end{array}$ \\
\hline 1 & $\begin{array}{c}\text { Single-borehole } \\
\text { extraction }\end{array}$ & 7.2 & 0.71 \\
2 & $\begin{array}{c}\text { Hydraulic slotting } \\
\text { extraction }\end{array}$ & 6.5 & 0.68 \\
\hline
\end{tabular}

index, but the method of hydraulic slotting for quick pressure relief, because of the larger pressure relief area and higher extraction efficiency, can make the residual gas quantity and residual gas pressure even lower.

\section{Conclusions}

(1) The differences between long-distance through-coal seam tunnels and underground coal mine roadway driving are analyzed. Compared with coal mine roadway driving, the work of long-distance through-coal seam tunnels generally has the characteristics of high degree of surrounding rock breakage, low degree of geological exploration, large cross-section of coal uncovering, tight time and space for implementing outburst prevention measures, strict control of surrounding rock deformation, etc. According to the outburst prevention characteristics needed for long-distance through-coal seam tunnels, this paper puts forward the method of networked slotting in long-distance through-coal seam tunnels for rapid pressure relief and outburst elimination

(2) The mathematical governing equation and gas extraction numerical model of the method of networked slotting in long-distance through-coal seam tunnels for rapid pressure relief and outburst elimination has been established. The extraction simulation optimization analysis has been carried out on the arrangement of borehole spacing and slot spacing arrangement in this method, and the results that have been obtained are the following: the optimal borehole arrangement spacing is $2.85 \mathrm{~m}$ and the optimal slot arrangement spacing is $3.1 \mathrm{~m}$

(3) The efficiency of gas extraction of the method of networked slotting in long-distance through-coal seam tunnels for rapid pressure relief and outburst elimination and the method of dense-borehole gas extraction have been compared and analyzed, and the reliability of the method of networked slotting in long-distance through-coal seam tunnels for rapid pressure relief and outburst eliminations has been verified. The field experimental data of two kinds of gas extraction methods in the through-coal seam tunnel show that compared with the single-borehole extraction method, the method of networked slotting in long-distance through-coal seam tunnels for rapid pressure relief and outburst elimination can shorten 
the extraction period by about $66 \%$, increase the net quantity of peak extraction by 3.55 times, and increase the total quantity of gas extraction by 1.26 times when the outburst prevention index is reached. Due to the larger pressure relief area and higher extraction efficiency, the residual content and residual pressure of gas with this method are even lower. The experimental results has verified the correctness of the numerical analysis results as well as the reliability of this method

\section{Data Availability}

The numerical simulation data used to support the findings of this study are available from the corresponding author upon request.

\section{Conflicts of Interest}

The authors declare that they have no conflicts of interest.

\section{Acknowledgments}

This paper is jointly funded by the Qinghai Transportation Science and Technology Project (No. 2020-01).

\section{References}

[1] D. Li, Y. Lu, Y. Rong et al., "Rapid uncovering seam technologies for large cross-section gas tunnel excavated through coal seams using directional hydraulic fracturing," Rock and Soil Mechanics, vol. 40, no. 1, pp. 363-370, 2019.

[2] B. Li, Q. Wu, and Z. Liu, "Identification of mine water inrush source based on PCA-FDA: Xiandewang coal mine case," Geofluids, vol. 2020, Article ID 2584094, 8 pages, 2020.

[3] D. Li, Y. Rong, S. Zhang, D. Zhou, and C. Guo, "Novel technology of large cross-section gas tunnel uncovering coal seam in Southwest China," Chinese Journal of Underground Space and Engineering, vol. 40, no. 1, pp. 363-370, 2019.

[4] X. H. Li, T. L. Li, Y. L. Gu, and Y. Y. Lu, Construction Technology of Uncovering Coal in Gas Tunnel, Chongqing University Press, Chongqing, 2005.

[5] D. Y. Jiang, C. Liu, G. Y. Zhang, and J. L. Zheng, "Technologies of whole cutting through coal seam and preventing collapse in highway tunnels," Rock and Soil Mechanics, vol. 26, no. 6, pp. 906-909, 2005.

[6] G. B. Wang and Y. N. Li, "Application of comprehensive survey technique to gas tunnel of highway," Rock and Soil Mechanics, vol. 32, no. 4, pp. 1273-1277, 2011.

[7] L. Cheng, Z. Ge, J. Chen, H. Ding, L. Zou, and K. Li, "A sequential approach for integrated coal and gas mining of closely-spaced outburst coal seams: results from a case study including mine safety improvements and greenhouse gas reductions," Energies, vol. 11, no. 11, p. 3023, 2018.

[8] L. Cheng, Z. Ge, B. Xia et al., "Research on hydraulic technology for seam permeability enhancement in underground coal mines in China," Energies, vol. 11, no. 2, p. 427, 2018.

[9] C. Liang, L. Yi-yu, G. Zhao-long, D. Hong, and Z. Ding-yun, "Initiation pressure calculation model and judgment criterion for hydraulic fracturing of inclined coal seam," Rock and Soil Mechanics, vol. 36, no. 2, pp. 444-450, 2015.
[10] Y. Y. Lu, Y. Z. Jia, J. R. Tang, and S. Chen-peng, "Mechanism of hydro fracture propagation control by no uniform pore pressure field," Journal of Northeastern University (Natural Science), vol. 37, no. 7, pp. 1028-1033, 2016.

[11] Y. J. Feng and H. P. Kang, "Hydraulic fracturing initiation and propagation," Chinese Journal of Rock Mechanics and Engineering, vol. 32, no. 2, pp. 3169-3179, 2013.

[12] W. Yaofeng, H. Xueqiu, W. Enyuan, and L. Zeng-yan, "Research progress and development tendency of the hydraulic technology for increasing the permeability of coal seams," Journal of China Coal Society, vol. 39, no. 10, pp. 1945-1955, 2014.

[13] J. Wang, Z. Wan, Y. Wang et al., "Effect of stress and moisture content on permeability of gas-saturated raw coal," Geofluids, vol. 2020, Article ID 8837758, 13 pages, 2020.

[14] J. Zhang, L. Si, J. Chen, M. Kizil, C. Wang, and Z. Chen, "Stimulation techniques of coalbed methane reservoirs," Geofluids, vol. 2020, Article ID 5152646, 23 pages, 2020.

[15] J. Liu, Z. Chen, D. Elsworth, H. Qu, and D. Chen, "Interactions of multiple processes during CBM extraction: a critical review," International Journal of Coal Geology, vol. 87, no. 34, pp. 175-189, 2011.

[16] Y. Wu, J. Liu, D. Elsworth, Z. Chen, L. Connell, and Z. Pan, "Dual poroelastic response of a coal seam to $\mathrm{CO}_{2}$ injection," International Journal of Greenhouse Gas Control, vol. 4, no. 4, pp. 668-678, 2010.

[17] K. T. Lim and K. Aziz, "Matrix-fracture transfer shape factors for dual-porosity simulators," Journal of Petroleum Science and Engineering, vol. 13, no. 3-4, pp. 169-178, 1995.

[18] H. Zhang, J. Liu, and D. Elsworth, "How sorption-induced matrix deformation affects gas flow in coal seams: a new FE model," International Journal of Rock Mechanics and Mining Sciences, vol. 45, no. 8, pp. 1226-1236, 2008.

[19] X. Cui and R. M. Bustin, "Volumetric strain associated with methane desorption and its impact on coalbed gas production from deep coal seams," AAPG Bulletin, vol. 89, no. 9, pp. 11811202, 2005.

[20] J. Liu, Z. Chen, D. Elsworth, X. Miao, and X. Mao, "Linking gas-sorption induced changes in coal permeability to directional strains through a modulus reduction ratio," International Journal of Coal Geology, vol. 83, no. 1, pp. 21-30, 2010.

[21] Y. Zhou, R. K. N. D. Rajapakse, and J. Graham, “A coupled thermoporoelastic model with thermo-osmosis and thermalfiltration," International Journal of Solids and Structures, vol. 35, no. 34-35, pp. 4659-4683, 1998.

[22] W. C. Zhu, C. H. Wei, J. Liu, H. Y. Qu, and D. Elsworth, "A model of coal-gas interaction under variable temperatures," International Journal of Coal Geology, vol. 86, no. 2-3, pp. 213-221, 2011.

[23] Y. Liu, J. Zhang, T. Zhang, and H. Zhang, "Optimal nozzle structure for an abrasive gas jet for rock breakage," Geofluids, vol. 2018, Article ID 9457178, 14 pages, 2018.

[24] D. Su, D. Zheng, and L. Zhao, "Experimental study and numerical simulation of dynamic stress-strain of directional blasting with water jet assistance," Shock and Vibration, vol. 2019, Article ID 1659175, 15 pages, 2019.

[25] D. Su, Y. Kang, D. Li, X. Wang, and F. Yan, "Analysis and numerical simulation on the reduction effect of stress waves caused by water jet slotting near blasting source," Shock and Vibration, vol. 2016, Article ID 5640947, 18 pages, 2016. 